\title{
Experiences of Low Gestational Weight Gain: A Phenomenological Study with Pregnant Women
}

\author{
Cynthia L. Murray ${ }^{*}$, Sherrill A. Conroy ${ }^{2}$ \\ ${ }^{1}$ School of Nursing, Memorial University of Newfoundland, St. John's, Canada \\ ${ }^{2}$ Faculty of Nursing, University of Alberta, Edmonton, Canada \\ Email: ${ }^{*}$ cindym@mun.ca
}

Received 3 September 2014; revised 18 October 2014; accepted 2 November 2014

Academic Editor: Alfred Maluwa, Kamuzu College of Nursing, University of Malawi, Lilongwe Campus, Lilongwe, Malawi

Copyright (C) 2014 by authors and Scientific Research Publishing Inc.

This work is licensed under the Creative Commons Attribution International License (CC BY). http://creativecommons.org/licenses/by/4.0/

(c) (†) Open Access

\begin{abstract}
Low maternal, gestational weight gain is associated with preterm birth, intrauterine growth restriction, low birthweight, small-for-gestational-age infants, neural tube defects, infant death, failure to initiate breastfeeding, and childhood asthma. The advantage of qualitative research is it can provide valuable insights for health care professionals into the experience and perceptions of low gestational weight gain from the vantage point of women with first-hand lived experience. In this Heideggarian interpretive phenomenological study, the meaning and experiences of weight gain for pregnant women with low gestational weight gain were explored. Data were collected through interviews with 10 pregnant women from Atlantic Canada. Conroy's pathway for interpretive phenomenology was utilized. A hermeneutical spiral of interpretation identified six patterns or major themes: confronting one's mortality; defending oneself against a permanent metamorphosis into a stranger; playing with fire and brimstone; slipping under the radar; trying to find peace; and riding an emotional roller coaster. The findings point to a war that is being waged over pregnant bodies with respect to weight that leaves pregnant women fending for themselves, apparently with little help from their health care providers. Implications of the findings for health practice, education, and research are discussed.
\end{abstract}

\section{Keywords}

Embodiment/Bodily Experiences, Heideggarian Interpretive Phenomenology, Lived Experience,

\footnotetext{
${ }^{*}$ Corresponding author.
} 


\section{Pregnancy, Weight Gain}

\section{Introduction}

Low maternal, gestational weight gain is associated with preterm birth, intrauterine growth restriction, low birthweight, small-for-gestational-age infants, neural tube defects, infant death, failure to initiate breastfeeding, and childhood asthma [1]-[4]. The health care costs of suboptimal gestational weight gains and associated sequelae are exorbitant. For example, the annual cost of preterm/low birth weight admissions totaled $\$ 5.8$ billion in the United States in 2001, which accounted for half of all expenditures for infant hospitalizations and a quarter of all costs for pediatric stays [5]. In 2000, Abrams, Altman, and Pickett [6] determined that only $30 \%-40 \%$ of American pregnant women gained within the Institute of Medicine (IOM) weight gain guidelines. More recently, the IOM ascertained that little had changed in this regard, with less than half of pregnant women in the United States gaining within the recommended weight gain ranges [4]. While gestational weight gains exceeding the recommendations have garnered greater attention from researchers, up to one-quarter of pregnant women in developed countries, including Canada, undergain in pregnancy [4] [7]-[9]. The purpose of this study was to explore the meaning and experiences of weight gain for pregnant women with low gestational weight gain. Phenomenological findings might help health care professionals understand a lived experience from the perspective of those who lived it, which could inform their practice. For instance, in two previous studies [10] [11], Heideggarian/interpretive phenomenological analyses revealed that some patients with multiple sclerosis relied on anecdotal accounts in decision making about the liberation procedure [10] and pregnant women who smoked during pregnancy reported feeling abandoned by their health care providers [11], which had implications for health care delivery. By listening to first-hand accounts of lived health experiences, health care professionals can "step into the shoes" of those who live these experiences and respond in a more meaningful manner.

\section{Methods}

The philosophical background of this study was Heideggarian interpretive phenomenology [12]. The goal of interpretive phenomenology is to gain a better understanding of human lived experiences [13]. Interpretive phenomenology is based on embodied knowledge or "knowing-how" the world works through the lived body [12] [14]. Details on the philosophical background of this study are published elsewhere [12]-[14]. Consistent with Heideggarian interpretive phenomenology, the main research question for this study was: What is the meaning and experience of low gestational weight gain for pregnant women?

\subsection{Setting}

This study was held in the Atlantic Canadian province of Newfoundland and Labrador (NL). The rate of low gestational weight gain in NL was calculated at 17\% in 2007 [7]. Every initial and follow-up interview for this study was conducted at a time and place determined by the participant. Three interviews were held in a secluded corner of a restaurant and the remaining interviews took place either in the first author's office or in the participant's home.

\subsection{Recruitment and Participants}

The sample for this study consisted of 10 pregnant women (i.e., 19 years of age or older), who were undergaining according to Health Canada guidelines, which are based on the IOM recommendations [4] [15]. Morse and Field [16] recommend a sample size of 6 - 10 participants for phenomenological studies in order to explore the experience in-depth. Purposive and snowball sampling were used to select participants with personal knowledge of the experience under study. Obstetricians and midwives in the region were contacted to seek their assistance with recruitment. The obstetricians and midwives were instructed to tell pregnant women, who met the inclusion criteria, about the study and explain that their decision of whether or not to participate in the study had no influence on their care. Pregnant women contacted the first author, who further explained the study. Interviews were scheduled with those meeting the inclusion criteria and expressing interest in being interviewed.

Of the 10 participants, one was in her early 20s, five were in their late 20s, and four were over the age of 30. Two of the women described their socioeconomic status as lower class and the rest were middle to upper class. 
With only two exceptions, the women had at least some university education. Seven of the pregnant women held undergraduate degrees and two of these women went on to graduate studies. At the time of the study, one woman was enrolled in a master's program, while the second woman had already graduated with a master's degree.

Apart from one student and one stay-at-home mother, the women worked full-time. Most of the women $(n=8)$ were married and two were living with their partner. Less than half $(n=4)$ of the participants were primiparous and six were multiparous. All of the women were White and had a "normal" pre-pregnancy weight (i.e., body mass index [BMI] $18.5-24.9 \mathrm{~kg} / \mathrm{m}^{2}$ ) according to Health Canada's [17] health risk classification system according to BMI. None of the participants reported smoking. At the time of their first interview, four of the women were in their third trimester and six were in their second trimester. Follow-up interviews took place during the third trimester and the first six months postpartum.

\subsection{Ethical Considerations}

This study was approved by the Health Research Ethics Board Panel B at the University of Alberta and the Human Investigations Committee of Memorial University of Newfoundland. Written informed consent was obtained by the first author before beginning the first interview. The information letter describing the study and the consent form were thoroughly reviewed with each participant. The participants were informed that a follow-up interview would take place to clarify any ambiguities about the experience and to obtain feedback on the preliminary findings. There was the potential risk for the participants of feeling upset while talking about their experiences and perceptions of gestational weight gain. None of the participants in this study became upset during the interviews. However, if a participant became upset, the first author would have asked the participant if she wanted to stop or reschedule the interview. The first author would have encouraged the participant to call a particular registered psychologist, who agreed to take referrals arising from the study. The participants were given a $\$ 30$ gift certificate redeemable at a major grocery store as a token of appreciation.

\subsection{Data Collection}

One initial face-to-face interview was held with each participant. A follow-up interview was also held with every participant, with one exception due to extenuating personal circumstances for the participant. The first author, who had extensive instruction/training in interpretive phenomenology in her $\mathrm{PhD}$ in Nursing program, conducted all of the interviews. Most of the interviews took about 30 to 60 minutes to carry out, but a few took 2 hours to complete. Nonstandard, spontaneous, open-ended questions were asked to obtain the women's stories of low gestational weight gain. Examples of questions included "Could you please tell me your story about gaining weight during pregnancy?" and "Could you please tell me a story about someone commenting on your weight in pregnancy?” Prompts were also used to delve into details of their stories (e.g., "Could you please tell me more about that?" and "How did that make you feel?"). Sociodemographic information was collected at the end of the first interview in order to describe the sample. Data collection ended once a good phenomenological gestalt in the text was reached as recommended by Kvale [18].

\subsection{Data Analysis}

Conroy's [14] pathway for interpretive phenomenology was used in this study. The pathway incorporates Heidegger's [19] hermeneutic spiral that depicts the process in which people build upon each other's interpretations and understandings. The pathway is not linear and there are unpredictable shifts between the aspects of the pathway [14]. The six aspects of the pathway are:

1) attending to footprints and concurrent preliminary interpretation;

2) in-depth interpretation;

3) second reader introduction to the narratives;

4) paradigm shift identification;

5) exemplar development; and

6) principle development.

In the first aspect, the first author simultaneously gathered data, began to interpret the data, and attended to the footprints. Conroy [14] referred to a person's contribution to the hermeneutical spiral as “footprints” (p. 5). All of the footprints blended together in the hermeneutical spiral. The second aspect involved in-depth interpretation. The participants' stories were interpreted in light of the following existentials: a) temporality (lived time); 
b) spatiality (lived space); c) corporality (lived body); d) relationality or communality (lived human relation); and e) mood [20] [21]. Tentative themes were identified. Second readers entered the hermeneutical spiral, in the third aspect, by auditing the interpretations to ensure that the themes fit with the data. Paradigm shifts, exemplars, and principles were identified in the fourth, fifth, and sixth aspects respectively. Conroy [14] explained that a paradigm shift is "a change in a way of 'seeing' and coping with the world", while an exemplar is "a case that demonstrates consistency in concerns, meanings, knowledge, and skills common to a participant's experiencing of the world” (pp. 31-32). In the last aspect, recommendations were made for health practice, education, and research.

\subsection{Rigor}

Guba and Lincoln's [22] [23] criteria for establishing rigor were used in this research. The criteria are credibility, fittingness, auditability, and confirmability. The sample consisted of women with first-hand knowledge about the lived experience. Specifically, the participants were pregnant women, who had the experience of gaining less weight than medically recommended. The study findings presented herein provide thick descriptions [24] of the lived experience. All research decisions and activities were documented in order to leave an audit trail. The initial interpretations were discussed with participants to ensure that their experiences were accurately described. The practice of member checking, whereby the participants validate the findings, at the end of a qualitative research study has been challenged by some authors [25] [27]. Given that the results of an interpretive phenomenological study involve synthesis within and across all participants' perspectives, an individual participant cannot validate the final interpretations [26] [27]. In this study, two researchers external to the study, who are proficient in interpretive phenomenological methodology, served as second readers by auditing the texts and final interpretations to ensure that the themes fit the data.

\section{Discussion of the Results}

A theme is a thread of meaning that penetrates the text [28] and patterns are comprised of interrelated themes. In this study, six overarching patterns each with accompanying themes were identified (see Table 1).

\subsection{Confronting One's Mortality}

The first pattern entitled confronting one's mortality encompassed two themes: a) coming to terms with a withering body; and $b$ ) disguising the animal body.

Table 1. Patterns and themes identified in the participants’ stories of low gestational weight gain.

\begin{tabular}{|c|c|}
\hline Pattern & Theme \\
\hline \multirow{2}{*}{ 1. Confronting one’s mortality } & Coming to terms with a withering body \\
\hline & Disguising the animal body \\
\hline \multirow{3}{*}{$\begin{array}{l}\text { 2. Defending oneself against a permanent } \\
\text { metamorphosis into a stranger }\end{array}$} & Feeling like a stranger \\
\hline & Attempting to preserve your body \\
\hline & Getting your body back \\
\hline \multirow{3}{*}{ 3. Playing with fire and brimstone } & Stressing the dangers of overgaining \\
\hline & Trying to manage a wild, out of control body \\
\hline & Dealing with morality \\
\hline \multirow{2}{*}{ 4. Slipping under the radar } & Downplaying low gestational weight gain \\
\hline & Overlooking periods of low gestational weight gain \\
\hline \multirow{3}{*}{ 5. Trying to find peace } & Becoming embroiled in a war between beauty ideals and the sanctity of motherhood \\
\hline & Finding a compromise \\
\hline & Defending yourself as a “good” mother \\
\hline \multirow{2}{*}{ 6. Riding an emotional roller coaster } & Emotional suffering \\
\hline & Coping \\
\hline
\end{tabular}


Coming to Terms with a Withering Body. While pregnancy evoked images of a blossoming and glowing body for the participants, they associated the postpartum body with a state of decline. The women grudgingly accepted that their bodies would not emerge from the experience of pregnancy unscathed. Coming to terms with a withering body is evident in the following direct quote from a participant:

The woman said her body was like a piece of art... blossoming and glowing... It does blossom or grow, but it also withers and that's the part that I see the most. I know it's part of the circle of life, but who wants to think about that? It can be depressing.

Disguising the Animal Body. The women noted that it is fashionable now to show off the pregnant belly, yet there is contempt for this trend in some quarters. They also touted the importance of beauty during pregnancy. Wanting to cover the pregnant body and feeling a strong need to be beautiful during pregnancy have a connection in that they both hide or disguise the animal body. Research informs us that negative reactions to the pregnant or breastfeeding body are often rooted deeply in the existential fear of death [29]. Disgust is generally displayed in response to stimuli that call attention, if only subconsciously, to our animal nature [30]. People tend to deny their similarity to animals because it makes our mortality apparent [30]. Goldenberg and colleagues [30] proposed that beauty is highly valued because"... it allows humans to transform the most threatening aspect of the self, the animal body, into a symbol through which one can acquire value by living up to cultural standards and thereby ward off our fear of death”(p. 210). These points about disguising the animal body are illustrated in the following quotation:

To my uncle's disgust... some women actually show their bellies... He's like, "I don't want to see that!" But it is perfectly acceptable to... show a little bit of your belly... It's less of a hidden thing... There's a whole industry out there now for women's fashions in pregnancy... There's stuff out there to make you feel pretty... You don't feel like you're put behind like a big, old tent anymore.

Historically, female bodies have been associated with nature, instinct, irrationality, unpredictability, sensuality, uncleanliness, and evil [31]. Pregnancy drags the personal and the body into the workplace [32] [33]. Several women in this study did not want their professional competence called into question. This also called for a concealment of the pregnant, animal body. The participant speaking below tried to hide her pregnancy from her co-workers as long as possible:

Being a woman in my workplace is still a bit unusual and being a pregnant woman is that much more unusual. So [I was] mainly just trying to make sure that there was no perception of... loss of competence or loss of focus.

Previous authors discussed how women are always mindful of how their bodies read to others [34] [35]. Concealing the pregnant body in the workplace has been described elsewhere [33] [36], as well as the expectation held by some people to hide the pregnant body in general [32] [37] [38].

\subsection{Defending Oneself against a Permanent Metamorphosis into a Stranger}

The second pattern entitled defending oneself against a permanent metamorphosis into a stranger included three themes: a) feeling like a stranger; b) attempting to preserve your body; and c) getting your body back.

Feeling Like a Stranger. The women felt somewhat like strangers in their own skin during their pregnancies. The excerpt below exemplifies this altered sense of being:

Sometimes it feels like... your body is becoming a stranger to you... You know it's you, but it's not you.

Young [39] noted, "The pregnant subject... is decentered, split, or doubled in several ways. She experiences her body as herself and not herself. Its inner movements belong to another being, yet they are not other...” (p. 160). Other researchers reported on how pregnancy changes the body so much that the pregnant participants felt they had a new body [40] [41].

Attempting to Preserve Your Body. The participants in this study tried to minimize the impact of pregnancy on their bodies. This included limiting "junk" food, exercising, preventing stretch marks, and trying to control the rate, amount, and pattern of weight gain. The following statements are examples of attempting to preserve your body:

Some people gain a lot of weight to the point where they don't even look like themselves. I have a friend... everything swelled up and people talked about that... People would say, "Oh my God, did you see her?" I do not want to be a big, pregnant woman... I want to be small. I want to go back to normal the day after I deliver. I don't want none of the sagginess or any of the stretch marks... I want to still keep my youthfulness-youthful body. 
The women's actions may be best understood against the backdrop of their sociocultural surroundings. The women were adamant that fat stigmatization had infiltrated experiences of pregnancy. Specifically, they reported that gaining weight in places other than the "belly" is frowned upon, which is consistent with previous research [37] [42]. They believed that women were blamed for this pattern of weight gain. These points are raised in the following quotation:

Society's attitude is if it's on your belly, you're a very active person and you're healthy.... People think that if you have weight on anywhere else, that you're eating too much or too much of the wrong things or... you're not active enough... Something's wrong and you're getting fat everywhere. You're just getting fat.

As a way of distancing themselves from the stigma of obesity that was pervasive in their lives, the women tended to psychologically separate themselves from the weight gain.

Self-esteem wise it's much better... [to gain weight only] in the front because then you can look at it and say, "It's not really me gaining the weight. The baby is gaining all the weight and that's okay."

Participants in other studies have voiced concern about being mistaken by others as being "fat" as opposed to being pregnant [33] [37] [40] [42].

Getting Your Body Back. The majority of the women suspected their bodies would never be quite the same as before. As one participant stated, "You never... get the original shape back. You just get a facsimile.” However, from their perspective not all bodily changes are created equal. Specifically, persistent weight retention, which promoted an ongoing sense of foreignness, would be unacceptable. One participant shared the following thoughts:

Permanent weight gain would probably be the most upsetting... If I can't lose all of the baby weight, that would be... a personal failure.

They discussed at length how the post-pregnancy body is denigrated by society at large. Aversion towards maternal bodies was linked with ageism and fatism. These ideas are demonstrated in the quotes that follow:

We live in a culture where it's bad to gain weight and to get older and... body changes during pregnancy can both make you look fatter... and it can also make you look... more matronly.

It's hugely societal pressure... Oh, I've got to get back to what I was because if I don't, I'm just not attractive anymore. I'm used up. I'm worn out. I'm a mom.

The desire to get your body back was mentioned by pregnant women in other studies [33] [36] [37].

\subsection{Playing with Fire and Brimstone}

The third pattern entitled playing with fire and brimstone subsumed three themes: a) stressing the dangers of overgaining; b) trying to manage a wild, out of control body; and c) dealing with morality.

Stressing the Dangers of Overgaining. While some of the participants acknowledged the risks of undergaining, they were generally more concerned about gaining too much. As mentioned in the quotation below, overgaining was referred to as one's worst fear:

People saying, “Watch it! You don't want to gain too much.”... that just makes it so much worse... somebody else noticing and realizing your worst fear.

In the following excerpt, dietary fat was lumped together with toxins and carcinogens:

The stuff I worry about is what to avoid... [like] tuna fish. They say pregnant women shouldn't eat [tuna fish] because of the mercury level... and foods with pesticides sometimes I am worried about. So I'm more aware of that and, well I am, and the fat content too.

Trying to Manage a Wild, Out of Control Body. To some extent, the participants felt helpless to control their weight gain and cravings compounded this situation. They were vigilant about their weight because they believed that the somewhat unpredictable and potentially dangerous nature of pregnancy weight gain could be a recipe for disaster. Here is one participant's musings about how she tried to manage her weight gain, but concluded that it was not under her control:

If I've learned nothing else it's that [weight gain] really was not in my control... The last couple of weeks I've been like, “That's it! I give up! I'm doing whatever I want!”... Now I know that's not always the case because of course if you're eating nothing but junk, you're gonna gain more weight.

They were also mindful of the difficulties many women face with long-term postpartum weight retention:

I worry about gaining a lot because my mother always told us growing up, "Oh, don't get fat!" and "Oh, I gained weight when I got pregnant and I never lost it."... I often say to my sister, "Mom has been on a diet for 
40 years and... it's never made much difference.”... I don't want to deprive myself for most of my life.

Dealing With Morality. It was clear from even a cursory glance at the transcripts that the women's experiences were steeped in moral terms. Over gaining, under gaining, and unhealthy eating practices (e.g., overindulging in food) were deemed to be immoral. The moral culpability of being "fat" was also brought up in Earle's [42] study. One participant in this study revealed the following:

If you were gaining too much, you'd be ashamed to tell anybody for fear... they would judge you... but equally you'd be ashamed... if you didn't think you were gaining enough weight because... people would judge you for not being a good mother and for valuing your appearance over the health of your child.

From the women's perspective, the health care professionals they encountered tried to steer clear of the topic of weight. Nevertheless, the women's stories indicated that covert paternalistic and moralistic attitudes toward weight might have been at play. Negative comments from health care providers about early pregnancy weight gain surfaced in another qualitative study [43]. Participants in this study made the following observations:

The scales are right out in the open... at both of my doctor's offices and so anybody in the waiting room can see you getting weighed and I found that was a bit intrusive... and I mean I can weigh myself. That's the way I feel about it. I always felt like I can weigh myself... with the couple people that have been really vocal about my weight gain, it made me kind of nervous that there's gonna be another person whose gonna say it and it would be public and the other thing I noticed the doctor never, never comments on the weight gain.

The nurse made a big, "Oh my!" because she had gained so much. Now she hardly gained anything in her first 20 weeks. She was extremely upset. She mentioned it in her... pregnancy class and many of them had... [a] similar experience where they gained a lot of weight at one weigh in and got a similar type of reaction from the nurse.

Women in the study were caught between a rock and a hard place. Many were fervently opposed to excessive weight gain, but they did not want to come across as a superficial or vain person. They tried to strike a balance between the sin of gluttony and the sin of vanity. One participant divulged the following:

Women get big and [get] stretch marks, which are a big thing cause, well, I'm not really a superficial person, but I do worry a bit about it.

The literature contends that the pursuit of a moral life is at the heart of the pursuit of health and wellness [44]. As one participant indicated below, citing the virtue of health helped the women walk the fine line between the two transgressions of gluttony and vanity:

I guess being conscious of my weight before that I became conscious of my weight with my pregnancy as well and it is more for my health and my baby's health to be.

\subsection{Slipping under the Radar}

The fourth pattern entitled slipping under the radar incorporated two themes: a) downplaying low gestational weight gain; and b) overlooking periods of low gestational weight gain.

Downplaying low gestational weight gain. Women in the study downplayed the significance of their undergaining. In some cases it was clear that they used defense mechanisms to shield themselves against anxiety related to undergaining. Many downplayed it by underscoring that they eat healthy food. Here are two participants' comments:

I used to... find myself wishing that my weight stayed the same... Deep down I didn't want to gain weight, which is a terrible thing to admit, but I forced myself.

I was eating less, but... I've been making a concentrated effort to eat better... foods. So I think that kind of balanced out.

Misinformation might have played a role for some of the women. The participant speaking below did not expect to start gaining weight until 20 weeks of gestation:

I'm expecting it [will] come at 20 weeks... I'm 16 weeks now. So I'm expecting another few weeks and I'll gain... I kind of eat the same as what I used to. I try to eat healthier... Well, in the mornings, I usually just have a cup of tea and probably a cookie, which is not very good. Sometimes, I might get a slice of toast.

Generally speaking, they were well versed in the number of food group servings required, but seemed to be less informed about caloric intake needs.

Overlooking Periods of Low Gestational Weight Gain. Allegedly, aside from periods of dramatic weight loss, their healthcare providers did not talk about low weight gain unless they were prompted. They believed 
their doctors were relying on other measures, but they felt out of the loop. They were concerned that weight was a neglected area of counseling. Weight gain seemed to be a nonissue for their physicians, yet it was of prime importance for them.

I certainly didn't get much... counseling on weight gain... Prenatal classes... had a great deal of literature... but it's really basically too late... Most people are in the home stretch [then]... My doctors didn't even give me the guidelines on... weight gain... It's been a surprisingly minor aspect of my prenatal care even though... for most women it's a fairly major part of the experience of being pregnant.

\subsection{Trying to Find Peace}

The fifth pattern entitled trying to find peace involved three themes: a) becoming embroiled in a war between beauty ideals and the sanctity of motherhood; b) finding a compromise; and c) defending yourself as a "good" mother.

Becoming Embroiled in a War Between Beauty Ideals and the Sanctity of Motherhood. Before the 1980s, the Virgin Mary was the trope for pregnant women in Western societies [45]. Mothers have long been revered as creators and selfless nurturers and consequently motherhood has been venerated as a sacred path [46] [47]. The participants were cognizant of two opposing societal pressures: a) pressure to be thin and beautiful; and b) pressure to sacrifice their bodies for the sake of motherhood and the common good. Pregnant women in prior research have mentioned similar opposing pressures [41]. The participants in this study felt tension to not only unselfishly gain weight, but also to stay beautiful. This fuelled ambivalent feelings toward weight gain. They also received mixed messages from people about their weight gain as shown below:

People have said, “Jeez, you aren't very big! You haven't gained very much weight!”... It's not a good thing... although some people say, "Oh you're lucky! You carry well. You aren't showing."

Less than a generation ago 'maternity fashion' would have been considered an oxymoron [32]. The women's narratives suggest that today's maternity fashion industry is a double-edged sword. It might be credited with liberating the pregnant body, which the women welcomed:

It's lovely to see it. Even older women... love the fashions now for pregnant women because everything is more tighter... One [older] woman goes, "I had more Moo-Moos than I knew what to do with. You just felt so hidden.

Donning the latest in maternity fashions boosted their self-esteem. Conversely, they felt it generated new, unrealistic pressures for pregnant women to be beautiful. One participant cautioned the following:

Pregnancy is out there now. It's the new thing. A doctor... told me he loves the clothes... because it highlights their belly... They're not hiding it, but at the same time I think... some of it's a little over the top because there's this idea that it's just the belly and it's not. It's your whole body that's preparing for a baby and sometimes it sends the wrong messages to people.

Finding a Compromise. In the midst of competing weight gain demands, the women eked out an existence by finding their own compromise. All of them focused on eating healthy food. Most of them believed that bearing pregnancy weight mainly on the "belly" (i.e., having a "baby bump”) was an excellent compromise. This is evident in the following remarks:

If it's all in the belly, then you don't feel that you're depriving the baby of anything. At the same time, you don't feel that you yourself are gaining the weight.

They preferred this distribution of weight gain because it was the ideal standard of beauty in pregnancy, as stated below:

People say, “Oh, you're all baby! That's so good! You're just all baby!” That's the ideal.

It mitigated their sense of foreignness and it made them feel good and healthy:

I feel like I still am in my own body as opposed to having all these huge changes occur and feeling foreign in my own skin... and a lot of people too say, "You look just like yourself, only you have this bump."... It makes me feel good... I feel healthy.

As explained in the following excerpt, it was commonly believed that they reaped other benefits:

I've had tons of people say to me, "You're just baby and that's great!" and "You're gonna have no problem bouncing back after and... you'll probably have an easy delivery.

Defending Yourself as a "Good" Mother. No matter what road the women took to reach a compromise, part of that journey involved defending themselves as 'good' mothers: 
She said, "How's the baby?" And I said, "Oh fine." And she said, "You haven't gained very much weight hey?"... And I said, "I've gained, I've gained 20 pounds.”... So now I'm telling people, "Look. I'm normal. [The] doctor says everything's fine." I shouldn't have to say that to people, but I feel pressure... I have to stand up for myself and say, "I'm not starving myself. There's nothing wrong with this baby."

Participants spoke at length about what is referred to in the literature as a centuries-old dichotomy between the fetish and the unruly mother [48]. They shared numerous examples of how society tries to regulate the behaviors of pregnant women. They felt under duress to comply with these norms:

"Are you sure you're eating?"... "Are you eating lots?” Like people have asked me that. My boyfriend's mother asked me the other day, "Are you eating enough?"... She's trying to force me to eat..." Please eat! Please eat more! You're eating for two!"

There's a lot of rules... People are like, "You had tuna? Oh my God! You can't eat sandwich meat. My God!”... It's like people are very, very like draconian.

Foucauldian self-governing behaviors of pregnant women have been described by other researchers, such as Fox, Heffernan, and Nicolson [38].

\subsection{Riding an Emotional Roller Coaster}

The sixth pattern entitled riding an emotional roller coaster had two themes: a) emotional suffering; and b) coping.

Emotional Suffering. Participants experienced feelings of guilt, stress, worry, uncertainty, and ambivalence about pregnancy weight gain. The following remarks capture some of these feelings:

I was always nervous [about] how much I had lost and the stress around trying to keep myself fed... and you would be stressing about losing weight and feeling like you're doing damage.

I gained a pound... and all of a sudden, I felt really fat... Just the emotional stress of feeling like I'm gaining weight... you look in the mirror and... your mind inflates it because you've gained a pound, which is nothing, but when you look in the mirror, you see a difference.

The women were subjected to a barrage of insensitive comments from other women if their weight gain was perceived to be either inadequate or excessive. This created a lot of stress and turmoil for the women and impacted their body image and self-esteem. They were astonished that other women, especially mothers, lacked empathy for their situation.

One co-worker really gets entertained... “Oh my God! You're huge! Can you get any bigger? You're going to bust!" And then another person used to say the same thing and this is a mother. So that's been an eye opener... I said to [husband's name]..." It's starting to bother me especially when it comes from women. You know, women protect each other and are there for each other." And I started to think, "I'm huge! I'm really huge!"

Everybody keeps saying... “You don't look very big!”... I'm crying at nights because... it's not like I'm trying to not gain weight, but like I just don't seem to.

[She said,] “Oh, my friend is... only 5 months pregnant and she's twice your size!”... It's been from a lot of different people saying the same sorts of things ... on a daily basis.

It's not obvious that I'm pregnant even now... When she heard I was 7 months... it was this look of shock, “Oh my God! Like really? Really? Really?”... I went home and cried cause... I didn't know what to think. Like is there something wrong with me?

Coping. The women's experiences were not entirely fraught with suffering and hardship. They coped by reconceptualizing weight and availing themselves of social support:

It was really hard because you're trained your whole life... to think weight gain is bad period. Any kind of weight gain is bad. So getting past that to accept that, "Okay. No. It's absolutely healthy and absolutely necessary," but the intellectual side warring with the emotional training of just feeling bad about gaining weight... .I bought myself some new clothes... and then I felt better and like, "Okay. I can do this. It's alright." So I adapted to the idea of gaining weight.

Support from my husband has been really critical... So even though I look at my belly [and] sometimes I'm like, “Ooh who is this? Who owns this body?”... he's always encouraging.

Finally, beauty was an important antidote to the burden of weight gain and bodily changes on their self-esteem:

It's very important to do whatever you can to make you feel good about yourself; whether it's having a pedi- 
cure... or making sure that your makeup is done and you feel pretty... I think that's really important because if you... feel attractive, then the weight gain becomes less of an issue... It's very important to do those things because you're changing so much.

\section{Discussion of the Implications}

The findings of this study have implications for health care practice, education, and research.

\subsection{Implications for Health Care Practice}

The pregnant women in this study highlighted that even though weight was of central importance to their experience of pregnancy, their health care providers were silent on the issue unless they were prompted. This communication void might have left room for misinformation to go unchallenged. Many of the pregnant women in this study responded to the opportunity to share their experience of weight gain as if a floodgate had been opened. Health care professionals need to make a supportive, nonjudgmental space teeming with openness and sensitivity for authentic dialogue to flourish with pregnant women.

This study also brought to the fore contemporary pressures on pregnant women to be thin and beautiful in pregnancy by only sporting a "baby bump". Health care professionals can help appreciate and celebrate the natural beauty of all bodies and their inherent imperfections. They need to take an active role in counteracting idealized images of unrealistic, perfect pregnant and post-pregnant bodies. Health care professionals need to examine their own patient education materials to see what messages they are sending about pregnant and maternal bodies. They also need to be cognizant of and mitigate the tremendous pressure our society places on women to be the quintessential "good" mother [46].

\subsection{Implications for Education}

While progress has been made in the area of communication skills training for students in health care, the findings of this study support the contention that more is needed, especially when it comes to sensitive topics [49]. The need for empathy, a nonjudgmental approach, and good communication skills are common curriculum threads for students in all health disciplines. These core topics should be addressed in interprofessional education projects. Also health care students must be knowledgeable about healthy weights and body image issues. They are strategically positioned to be future agents for societal changes that foster healthy weights and healthy body images.

\subsection{Implications for Research}

Given the alleged silence of health care providers for the pregnant women in this study, qualitative research should be conducted with health care professionals that work with pregnant women. This might shed some light on why maternal, gestational weight was apparently a neglected area of patient education. Qualitative research should also be carried out with partners of pregnant women who are undergaining. This also might provide valuable insights into the phenomenon. On a final note, qualitative research on the experience of overgaining in pregnancy is also needed.

\section{Conclusion}

This study was conducted to address the dearth of research on the experience of low maternal, gestational weight gain. The findings point to a war that is being waged over pregnant bodies with respect to weight that leaves pregnant women fending for themselves, apparently with little help from their health care providers. Pregnancy weight spoke to who they were as women and mothers. One's weight influenced how they perceived themselves and how others perceived them. The participants' behaviors made sense given their societal background that values a "good" mother, as well as thinness, physical beauty, and youth. The findings of the study might help health professionals attain a better understanding of the experience of low weight gain in pregnancy. With a better understanding of the experience, health professionals can help pregnant women as they navigate the anti-“fat" waters around them. 


\section{Acknowledgements}

The first author acknowledges receipt of funding for this study from the Association of Registered Nurses of Newfoundland and Labrador (ARNNL) and the Newfoundland and Labrador Nurses' Union (NLNU). The authors sincerely thank the participants for giving their time and valuable contributions to the study.

\section{Author's Note}

This article stems from a study conducted by the first author for her $\mathrm{PhD}$ in Nursing degree from the University of Alberta under the supervision of Dr. Sherrill Conroy.

\section{References}

[1] Davis, R.R. and Hofferth, S.L. (2012) The Association between Inadequate Gestational Weight Gain and Infant Mortality among U.S. Infants Born in 2002. Maternal and Child Health Journal, 16, 119-124. http://dx.doi.org/10.1007/s10995-010-0713-5

[2] Viswanathan, M., Siega-Riz, A.M., Moos, M.K., et al. (2008) Outcomes of Maternal Weight Gain. Evidence Report/ Technology Assessment, 168, 1-223.

[3] Yang, W., Carmichael, S.L., Tinker, S.C. and Shaw, G.M. (2012) Association between Weight Gain during Pregnancy and Neural Tube Defects and Gastroschisis in Offspring. Birth Defects Research Part A: Clinical and Molecular Teratology, 94, 1019-1025. http://dx.doi.org/10.1002/bdra.23057

[4] Institute of Medicine and National Research Council (2009) Weight Gain during Pregnancy: Reexamining the Guidelines. The National Academies Press, Washington DC.

[5] Russell, R.B., Green, N.S., Steiner, C.A., et al. (2007) Cost of Hospitalization for Preterm and Low Birth Weight Infants in the United States. Pediatrics, 120, e1-e9. http://dx.doi.org/10.1542/peds.2006-2386

[6] Abrams, B., Altman, S.L. and Pickett, K.E. (2000) Pregnancy Weight Gain: Still Controversial. The American Journal of Clinical Nutrition, 71, 1233S-1241S.

[7] Crane, J., White, J., Hutchens, D., Burrage, L. and Murphy, P. (2007) The Effects of Gestational Weight Gain by Body Mass Index on Obstetric and Neonatal Outcomes. American Journal of Obstetrics and Gynecology, 197, S88-S88. http://dx.doi.org/10.1016/j.ajog.2007.10.291

[8] Kowal, C., Kuk, J. and Tamim, H. (2012) Characteristics of Weight Gain in Pregnancy among Canadian Women. Maternal and Child Health Journal, 16, 668-676. http://dx.doi.org/10.1007/s10995-011-0771-3

[9] Martin, J.A., Hamilton, B.E., Osterman, M.J.K., Curtin, S.C. and Mathews, T.J. (2013) Births: Final Data for 2012. National Vital Statistics Reports, 62, 1-87. http://www.cdc.gov/nchs/births.htm

[10] Murray, C.L., Ploughman, M., Harris, C., Hogan, S., Murdoch, M. and Stefanelli, M. (2014) The Liberation Procedure Decision Making Experience for People with Multiple Sclerosis. Global Qualitative Nursing Research, 1, 1-13. http://dx.doi.org/10.1177/2333393614551413

[11] Murray, C.L., Small, S. and Burrage, L. (2014) The Lived Experience of Smoking in Pregnancy. Open Journal of Nursing, 4, 762-773. http://dx.doi.org/10.4236/ojn.2014.411082

[12] Heidegger, M. (1962) Being and Time. Harper \& Row, New York.

[13] Bergum, V. (1991) Being a Phenomenological Researcher. In: Morse, J., Ed., Qualitative Nursing Research: A Contemporary Dialogue, Sage, Newbury Park, 43-57.

[14] Conroy, S.A. (2003) A Pathway for Interpretive Phenomenology. International Journal of Qualitative Methods, 2. http://www.ualberta.ca/ iiqm/backissues/2 3final/pdf/conroy.pdf

[15] Health Canada (2010) Prenatal Nutrition Guidelines for Health Professionals: Gestational Weight Gain. Health Canada, Ottawa. http://www.hc-sc.gc.ca/fn-an/nutrition/prenatal/ewba-mbsa-eng.php\#a2

[16] Morse, J.M. and Field, P.A. (1995) Qualitative Research Methods for Health Professionals. Sage, London.

[17] Health Canada (2012) Body Mass Index (BMI) Nomogram. Health Canada, Ottawa. http://www.hc-sc.gc.ca/fn-an/nutrition/weights-poids/guide-ld-adult/bmi_chart_java-graph_imc_java-eng.php

[18] Kvale, S. (1983) The Qualitative Research Interview: A Phenomenological and a Hermeneutical Mode of Understanding. Journal of Phenomenological Psychology, 14, 171-196. http://dx.doi.org/10.1163/156916283X00090

[19] Heidegger, M. (1998) Pathmarks. Cambridge University Press, Cambridge.

[20] van Manen, M. (1990) Researching Lived Experience: Human Science for an Action Sensitive Pedagogy. Althouse, London. 
[21] Conroy, S.A. and Dobson, S. (2005) Mood and Narrative Entwinement: Some Implications for Educational Practice. Qualitative Health Research, 15, 975-990. http://dx.doi.org/10.1177/1049732305279072

[22] Guba, E.G. and Lincoln, Y.S. (1981) Effective Evaluation. Jossey-Bass, San Francisco.

[23] Guba, E.G. and Lincoln, Y.S. (1989) Fourth Generation Evaluation. Sage, Newbury Park.

[24] Denzin, N.K. (1989) Interpretive Interactionism. Sage, Newbury Park.

[25] Angen, M.J. (2000) Evaluating Interpretive Inquiry: Reviewing the Validity Debate and Opening the Dialogue. Qualitative Health Research, 10, 378-395. http://dx.doi.org/10.1177/104973230001000308

[26] Horsburgh, D. (2003) Evaluation of Qualitative Research. Journal of Clinical Nursing, 12, 307-312. http://dx.doi.org/10.1046/j.1365-2702.2003.00683.x

[27] Morse, J.M. (1998) Validity by Committee. Qualitative Health Research, 8, 443-445. http://dx.doi.org/10.1177/104973239800800401

[28] Lindseth, A. and Norberg, A. (2004) A Phenomenological Hermeneutical Method for Researching Lived Experience. Scandinavian Journal of Caring Sciences, 18, 145-153. http://dx.doi.org/10.1111/j.1471-6712.2004.00258.x

[29] Goldenberg, J.L., Goplen, J., Cox, C.R. and Arndt, J. (2007) “Viewing” Pregnancy as an Existential Threat: The Effects of Creatureliness on Reactions to Media Depictions of the Pregnant Body. Media Psychology, 10, 211-230. http://dx.doi.org/10.1080/15213260701375629

[30] Goldenberg, J.L., Pyszczynski, T., Greenberg, J. and Solomon, S. (2000) Fleeing the Body: A Terror Management Perspective on the Problem of Human Corporeality. Personality and Social Psychology Review, 4, 200-218. http://dx.doi.org/10.1207/S15327957PSPR0403_1

[31] Hutchinson, M.G. (1994) Imaging Ourselves Whole: A Feminist Approach to Treating Body Image Disturbance. In: Fallon, P., Katzman, M.A. and Wooley, S.C., Eds., Feminist Perspectives on Eating Disorders, The Guildford Press, New York, 152-168.

[32] Longhurst, R. (2005) (Ad)dressing Pregnant Bodies in New Zealand: Clothing, Fashion, Subjectivities and Spatialities. Gender, Place and Culture, 12, 433-446. http://dx.doi.org/10.1080/09663690500356842

[33] Bailey, L. (2001) Gender Shows: First-Time Mothers and Embodied Selves. Gender \& Society, 15, 110-129. http://dx.doi.org/10.1177/089124301015001006

[34] Gadow, S. (1994) Whose Body? Whose Story? The Question about Narrative in Women’s Health Care. Soundings, 77, 295-307.

[35] Lupton, D. (1999) Risk and the Ontology of Pregnant Embodiment. In: Lupton, D., Ed., Risk and Sociocultural Theory, Cambridge University Press, Cambridge, 59-85.

[36] Upton, R.L. and Han, S.S. (2003) Maternity and Its Discontents. Journal of Contemporary Ethnography, 32, 670-692. http://dx.doi.org/10.1177/0891241603257596

[37] Johnson, S., Burrows, A. and Williamson, I. (2004) “Does My Bump Look Big in This?” The Meaning of Bodily Changes for First-Time Mothers-To-Be. Journal of Health Psychology, 9, 361-374. http://dx.doi.org/10.1177/1359105304042346

[38] Fox, R., Heffernan, K. and Nicolson, P. (2009) “I Don’t Think It Was Such an Issue Back Then”: Changing Experiences of Pregnancy Across Two Generations of Women in South-East England. Gender, Place \& Culture: A Journal of Feminist Geography, 16, 553-568. http://dx.doi.org/10.1080/09663690903148424

[39] Young, I.M. (1990) Throwing like a Girl and Other Essays in Feminist Philosophy and Social Theory. Indiana University Press, Bloomington.

[40] Clark, A., Skouteris, H., Wertheim, E.H., Paxton, S.J. and Milgrom, J. (2009) My Baby Body: A Qualitative Insight into Women's Body-Related Experiences and Mood during Pregnancy and the Postpartum. Journal of Reproductive and Infant Psychology, 27, 330-345. http://dx.doi.org/10.1080/02646830903190904

[41] Chang, S.R., Chao, Y.M. and Kenney, N.J. (2006) I Am a Woman and I'm Pregnant: Body Image of Women in Taiwan during the Third Trimester of Pregnancy. Birth, 33, 147-153. http://dx.doi.org/10.1111/j.0730-7659.2006.00087.x

[42] Earle, S. (2003) “Bumps and Boobs”: Fatness and Women’s Experiences of Pregnancy. Women's Studies International Forum, 26, 245-252. http://dx.doi.org/10.1016/S0277-5395(03)00054-2

[43] Nash, M. (2012) Weighty Matters: Negotiating “Fatness” and "In-Betweenness” in Early Pregnancy. Feminism \& Psychology, 22, 307-323. http://dx.doi.org/10.1177/0959353512445361

[44] Conrad, P. (1994) Wellness as Virtue: Mortality and the Pursuit of Health. Culture, Medicine and Psychiatry, 18, 385401. http://dx.doi.org/10.1007/BF01379232

[45] Allara, P. (1994) “Mater” of Fact: Alice Neel’s Pregnant Nudes. American Art, 8, 6-31. http://dx.doi.org/10.1086/424213 
[46] Thurer, S. (1995) The Myths of Motherhood: How Culture Reinvents the Good Mother. Penguin, New York.

[47] Kristeva, J. (1980) Motherhood according to Giovanni Bellini (Gora, T., Jardine, A. and Roudiez, L.S. Trans.). In: Roudiez, L.S., Ed., Desire in Language: A Semiotic Approach to Literature and Art, Columbia University Press, New York, 237-270.

[48] Kukla, R. (2005) Mass Hysteria: Medicine, Culture, and Mothers’ Bodies. Rowman \& Littlefield, Lanham.

[49] Chen, R.P. (2011) Moral Imagination in Simulation-Based Communication Skills Training. Nursing Ethics, 18, 102111. http://dx.doi.org/10.1177/0969733010386163 
Scientific Research Publishing (SCIRP) is one of the largest Open Access journal publishers. It is currently publishing more than 200 open access, online, peer-reviewed journals covering a wide range of academic disciplines. SCIRP serves the worldwide academic communities and contributes to the progress and application of science with its publication.

Other selected journals from SCIRP are listed as below. Submit your manuscript to us via either submit@scirp.org or Online Submission Portal.
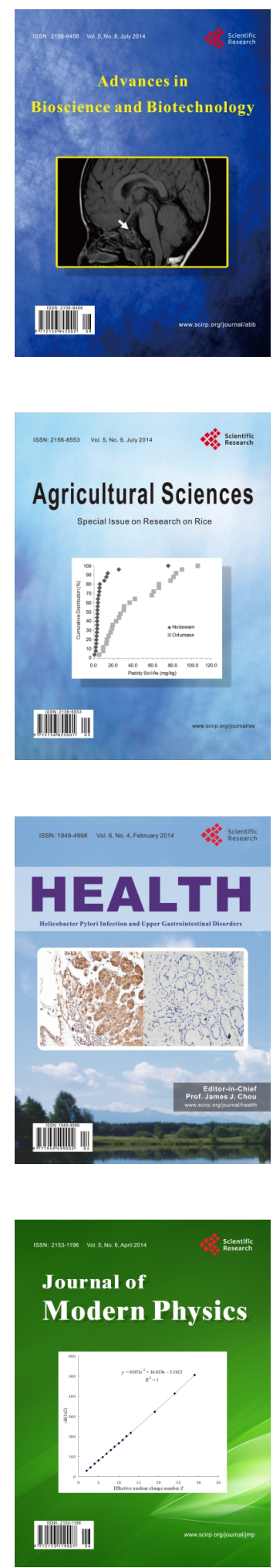
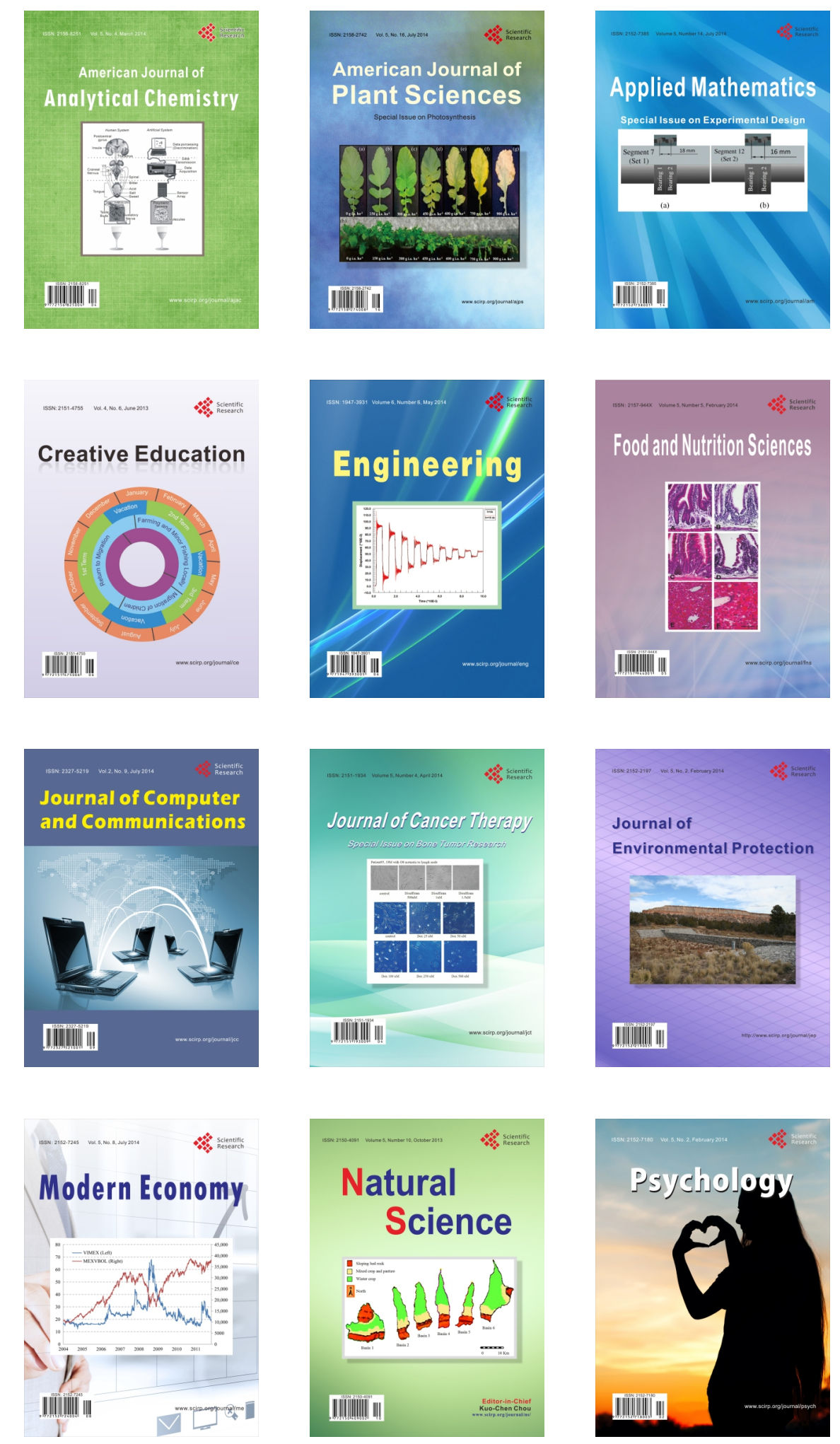